\title{
Solid Waste Utilization in Foundries and Metallurgical Plants
}

\author{
Jan Jezierski and Krzysztof Janerka \\ Department of Foundry, Silesian University of Technology \\ Poland
}

\section{Introduction}

The issue of waste management and utilization in foundries and metallurgical plants covers a lot of completely different materials in various forms (solid, liquid or gaseous). In this chapter, solid waste utilization is described based on the experiments and industrial experiences of Department of Foundry, Silesian University of Technology. The first part of the chapter introduces the readers into the subject of pneumatic powder injection into liquid metal process. It is a method widely used to utilize solid wastes in foundries and steel plants giving good technological and economic results. The casting production process is inseparably connected with pollutants emission into the environment, that is into air, water, soil and also noise emission. The fumes and gases from coke-fired furnaces are deposited in the air as well as other pollutants created when metal is molten in electric furnaces. Their amount can be limited by use of the modern high efficiency filters but the amount of dusts to deposit on waste dumps consequently increases. The water contaminations are caused by open melting furnaces cooling systems. The solid wastes from various production stages (moulding mass de-dusting, furnace de-dusting, blast cleaners de-dusting, slag etc.) are deposited on waste dumps. The latter can be utilized after granulation process as a road building material whereas furnace dusts are treated in recirculation into furnace systems decreasing their final quantity and improving utilization of some important elements, mainly iron (Fiore et al., 2008; Lee \& Song, 2007; Salihoglu et al., 2007; Fu \& Zhang, 2008).

\section{Powder pneumatic injection into liquid metal}

Materials introduction into foundry furnaces where there is a solid charge at the beginning and liquid alloy at the end of the melting process, can be operated by many ways. The introduction method depends on furnace construction (cupola, electric induction furnace, electric arc furnace etc.), the form of the powder introduced (dust, granulate, briquettes) and its chemical composition and foundry plant mechanization level (Holtzer et al., 2006; Jezierski \& Janerka, 2008).

The most often used are:

- introduction by hand for the small furnaces and small quantities of materials introduced (chemical composition correction),

- mechanical introduction with use of vibratory conveyors into charging hopper or dosing devices. Most often blocks or briquettes are introduced this way along with the solid charge, 
- pneumatic introduction of powdered material with carrier gas. This method is one of the pneumatic conveying applications. The liquid metal inside furnace or ladle replaces the typical pneumatic conveying receiving device. Powdered material is directly introduced into metal bath by means of pneumatic feeder and through pipes ended with an injection lance (Holtzer, 2005).

The two first methods mentioned require a special material pre-treatment which means it must be de-dusted or granulated or briquetted. They are not appropriate for the introduction of dusty fractions because of possibility of environmental pollution and the inefficiency of the metallurgical processes (the dusts are easily sucked out of furnace). Moreover, it should be emphasized that the most commonly used are waste materials in form of dust and their granulation or briquetting requires additional devices which increases total production costs. During pneumatic injection, the use of fine material particles causes a large contact surface between them and liquid metal and consequently high dissolution rates of material. Additionally, the lance is introduced inside liquid bath that eliminates environment dustiness problem and process is intensified by particles and metal mutual movement, forced by carrier gas stream. Finally, it causes significant physical chemical processes rate increase when compared to hand operated or mechanical introduction. These advantages caused that powdered materials pneumatic injection is used in the following processes (Jezierski \& Janerka, 2001; Cholewa, 2008):

- liquid cast iron recarburization inside electric arc furnaces and cupolas (the solid wastes from carbon materials production processes can be utilized),

- desulphurization and dephosphorization of alloys inside ladles and electric arc furnaces,

- alloy additions introduction into liquid metal inside ladles, electric arc furnaces and cupolas (the possibility of utilization of dusts from alloy additions production),

- alloys inoculation or refining and liquid composites production,

- inoculants introduction inside the liquid metal stream during mouldings pouring in,

- slag foaming inside electric arc furnaces during steel production,

- dusts recycling from cupolas and electric arc furnaces de-dusting systems,

- coal dust injection into blast furnaces,

- $\quad$ waste plastics utilization by their injection into blast furnaces.

Many factors determine the correct powder pneumatic injection process. These are: pneumatic transportation parameters, carrier gas and material mass flow, solid-gas mixture mass concentration, gas and particles velocity on the lance outlet. These parameters depend on feeding device construction which should give a possibility of changing individual parameters. The liquid metal parameters (the initial bath temperature, chemical composition, metal bath mass), the grade of powdered material and carrier gas play together an important role, too (Engh \& Larsen, 1979; Janerka \& Jezierski, 2002). The kind of carrier gas used depends on the process itself, the reagent being introduced and the furnace. The powdered material carriers are usually: compressed air, argon or nitrogen. When carbon materials or dusts are introduced air is mostly employed. Inoculants introduction, desulphurization and alloy additions introduction into ladle requires argon usage. When compressed air is used (because of its dampness) the filters, dehydrators or driers are used. The powdered materials introduced into liquid metals can be divided into: powders insoluble in liquid metal (forming slag) and soluble reagents which are assimilated by metal or refine it. This is both for materials utilized earlier in metallurgical processes and for dusts recycled from various production processes. Powders are characterized by physical 
chemical properties as melting point, gas saturation and solubility inside liquid metal. Their dampness should be minimal $(<0.1 \%)$ because of possibility of hydrogen assimilation by liquid metal. In order to design devices properly and select pneumatic injection parameters properly, the bulk density and compactibility (the level of density) of the injected materials must be known. It is important to ensure that the material will not suspend in feeders and silos which can cause instability in dosing devices. This is particularly important for dusts created in metallurgical furnaces which possess very strong internal bonds (Janerka, 2010; Kanafek et al., 1999). As mentioned earlier, the important element of the powder injection process is a feeder, where the mixing of carrier gas and powder as well as subsequent diphase stream conveying take place. The powder injection setups used nowadays are of various constructional and functional designs. The powder feeders should be characteristic for powder feeding stability, small carrier gas consumption and be hermetic. The feeders can be divided into two groups - gravitational and pressurized. The gravitational ones work on loose powder pouring basis. The material portioned with mechanical feeders (with sectors, cells or feeding screw) is introduced into pipeline and transported with carrier gas stream. Because the feeders are not completely hermetic when the overpressure on lance outlet appears (metallostatic pressure), these feeders can be used only when the powder is introduced solely on the liquid metal surface. In pressure feeders the material into pipeline introduction is intensified by overpressure in the upper part of the feeder. Solutions like that are used when the material is transported through longer pipeline and when the injection lance is submerged into liquid metal (Janerka, 2010; Kokoszka et al., 1999). One of the features that differ the classic pneumatic conveying (where the receiver is a silo) from pneumatic injection process (where the receiver is liquid metal) are the working parameters. For the pneumatic injection the range of transportation parameters differs from those for pneumatic conveying. The pneumatic conveying is determined mostly by the economic factors which can be obtained for high solid-gas mixture mass concentration (this parameter is a quotient of material mass flow and gas mass flow) and small diphase stream velocity. In injection process technological parameters play the most important role. Therefore high flow velocity on the lance outlet (Approx. $70 \div 120 \mathrm{~m} / \mathrm{s}$ ) to ensure high stream energy to achieve its deeper penetration into liquid metal is applied. The mixture mass concentration is usually from 8 to $20 \mathrm{~kg}$ of solid per $\mathrm{kg}$ of gas (Janerka, 2003).

\subsection{Recarburization of liquid metal}

The projects targeted to limit waste generation may cover the solid metal charge for cast iron production change and the pig iron can be replaced with steel scrap. The pig iron share may reach up to $75 \%$ of the charge mass. The pig iron is usually blast furnace product and the carbon content varies from 3.5 to $4.5 \% \mathrm{C}$. There are two main pig iron grades: steelmaking pig iron and foundry pig iron which are supplied to foundry in the form of pigs. The foundry pig iron can be further divided into: hematite, semi-hematite, normal, phosphoric and special for ductile iron production. The pig iron production process generates significant waste amounts and is energy-consuming. It is possible to produce cast iron with no pig iron at all (synthetic cast iron). In this case it is necessary to compensate carbon deficit when the pig iron is replaced by steel scrap. The greater utilization of the steel scrap which is waste material may be considered both from the ecological and the economic point of view. The price of steel scrap depending on the world situation is three times less than foundry pig iron. The cast iron smelting on the steel scrap base only forces to more than 3\% carbon content increase. In this case the carburizer mass should be around 3.8 to $5 \%$ of the 
metallic charge mass. This amount depends on carburizer grade and the recarburization method employed. On the basis of the estimated carbon content in grey iron, steel scrap, pig iron and carburizer one can proceed with the calculations of the specific charge materials. To reach $3.2 \% \mathrm{C}$ content in iron when the heat is made only with the steel scrap, $74 \%$ pig iron and $26 \%$ steel scrap should be charged. When $100 \%$ of steel scrap is used and the goal is $3.2 \% \mathrm{C}$ in the final alloy, the introduction of $4.2 \%$ carburizer is necessary. These proportions may vary of course when some portion of the process scrap with the carbon content Approx. $3.2 \%$ is introduced into solid charge (Skoczkowski, 1998; Janerka, 2010). The most often used carburizers are natural graphite, anthracite, synthetic graphite and petroleum coke. Graphite is a natural mineral and occurs as a $72-80 \%$ of carbon rich ore. Its natural colour is glossy black or steel black. Dependably on amount and kind of impurities in ore the natural graphite is produced by means of special enrichment. It may be achieved by sorting inside the air stream and flotation (Janerka et al., 2009). Anthracite is a product of high plant substances carbonification which contain of $92-97 \%$ of elemental carbon. It is characterized by tar black lustre, high mechanical strength and low volatile parts content of 3-8\%. Synthetic graphite is the name given to graphite obtained during high-temperature process (graphitization) of the coke (petroleum, coal or pitch) and anthracite. The properties of the synthetic graphite and its structure degree of order depend on both input material and the final treatment temperature. Petroleum coke is a solid carbonaceous product obtained during thermal treatment of the oil distillation residues. The input product for the coking are heavy residues from various stages and methods of the crude oil refining (Janerka et al. 2009; Janerka, 2010).

The production of those materials is in some degree connected with environment pollution. It should be emphasized that the necessary amount of carburizer to produce $1 \mathrm{t}$ of cast iron is relatively small and equals $40-50 \mathrm{~kg}$. The most environmental friendly carburizers are natural graphite and anthracite. These are minerals which are only mechanically ground and calcined when only the volatile parts and some sulphur compounds are emitted into the atmosphere. Petroleum coke and synthetic graphite, which require high-temperature processing are much more nuisance to the environment. Materials from the scrap graphite or carbon electrodes grinding process, materials from graphite linings used in various industry branches offered by many suppliers, can also be used as carburizers. Foundries which possess electric arc furnaces we can use their own scrap electrodes as a carburizer . The production wastes from electrode manufacturers can be also used as carburizers. Mostly these are dusts from electro-filters with very big carbon content of 97-99\%C.

The essential parameter which characterizes the recarburization process from the technological point of view is its efficiency (recarburization effectiveness, carbon by liquid metal assimilation ratio). This parameter determines recarburization time and the carburizer amount to be introduced to obtain the planned carbon content increase. The efficiency (the effectiveness) of the recarburization is given by equation (Janerka 2010, Chojecki et al. 2002):

$$
E=M_{m} \frac{C_{k}-C_{p}}{M_{n} \cdot C_{n}} \cdot 100 \% .
$$

where: $C_{p}$ - the initial carbon content, $\%, C_{k}$ - the final carbon content, $\%, M_{m}$ - mass of metal, $\mathrm{kg}, \mathrm{M}_{\mathrm{n}}$ - mass of carburizer, $\mathrm{kg}, \mathrm{C}_{\mathrm{n}}$ - carbon content in carburizer, $\%$.

The carburizer introduction can be realized by its addition into solid charge, onto liquid metal surface, onto liquid metal stream or on the ladle bottom. In these cases the carburizer granulation should be something between 1 and $6 \mathrm{~mm}$ (with no dust in it). The carburizer 
introduction into solid charge can be realized in electric induction and arc furnaces and cupolas, too. It is a method which does not require any additional investments to buy the recarburization devices. The high recarburization level can be achieved by this method with no melting time extension at all. The use of that method allows not only to correct the carbon content in alloy but to produce the synthetic iron, too. Therefore it is often used for the cast iron production.

The carburizer introduction onto liquid metal bath surface is the most common recarburization method for the electric induction furnaces both for synthetic cast iron and for cast iron made on a pig iron production method. It is because after the solid charge is melted the sample for chemical analysis is taken and on its basis the real carbon deficit is estimated. Moreover, in the electric induction furnaces when the charge is molten, the continuous electromagnetic stirring occurs what causes an increase of the process efficiency. For the cupolas and electric arc furnaces the carburizer introduction in carrier gas stream is often used and the fine (dusty) fractions of carburizers can be utilized.

The recarburization setup example is presented in Fig. 1. Its main part is a pressure container (1) of 0.25 to $1.0 \mathrm{~m}^{3}$ capacity (Janerka, 2010; Kanafek et al., 1999; Kokoszka et al., 1999). The bell door is situated in the upper part, whereas the mixing chamber (3) is situated at the bottom. The pressure container is equipped with decompression valve which allows to decompress the container when the working cycle is finished. The air pressure above the material being conveyed is regulated by means of the reducer (4). The air supply is started and stopped with the main valve (10) operation. All the valves can be operated from container control switchboard (2) or from the control panel situated in the furnace control room. The container is mounted on the extensometric scales (5) and their recordings are displayed on the control switchboard (2). The carburizer is transported through a pipe (11) ended with the injection lance (13) inserted into electric arc furnace (14) and submerged into liquid metal. The lance can be mounted on the manipulator (12) which allows its automatic introduction into liquid metal. This method makes the work safer and guarantees better process repeatability.

The silo (7) with the carburizer can be situated above the feeder and it can have 24hours or shift working capacity. The screening sieve (8) should be mounted at the top of container to stop the impurities and oversize. The bottom silo (7) part is a pneumatically driven damper (slide or swivel). Between damper (6) and chamber feeder (1) the compensator is necessary to eliminate silo influence on the weighing system. The carburizer is supplied by manufacturers mostly in big-bags of $1 \mathrm{~m}^{3}$ capacity. On the basis of the author's experiments (Janerka 2010; Janerka et al. 2010) and literature overview (Kosowski, 1982; Przeworski, 1986) an analysis of the influence of the introduction method (SC - carburizer into solid charge addition, $\mathrm{S}$ - addition onto metal surface, PI - pneumatic injection), furnace type (IH - induction furnace, EAF - electric arc furnace) and carburizer grade (GS - synthetic graphite, GE - ground electrodes scrap) on the recarburization efficiency was carried out (Fig. 2.). Of course these are average results, because there are many factors which can change those values all the time. However, some conclusions can be put forward. When the recarburization efficiencies recorded in induction furnaces for the synthetic graphite and ground electrodes scrap are compared, it can be seen that they are even higher for the electrodes scrap.

It is probably an effect of the recarburization method employed but it show that this waste material makes up the full value of carburizer. The next remark is connected to the recarburization method. The introduction of carburizer with solid charge in induction 
furnace allows the foundry to achieve the efficiency respectively 92 and $83 \%$ and for the addition onto metal surface the process efficiency is reduced by Approx. 6\%. For the EAF when the carburizer is added with solid charge the efficiency is 10 to $15 \%$ less than for induction furnace.

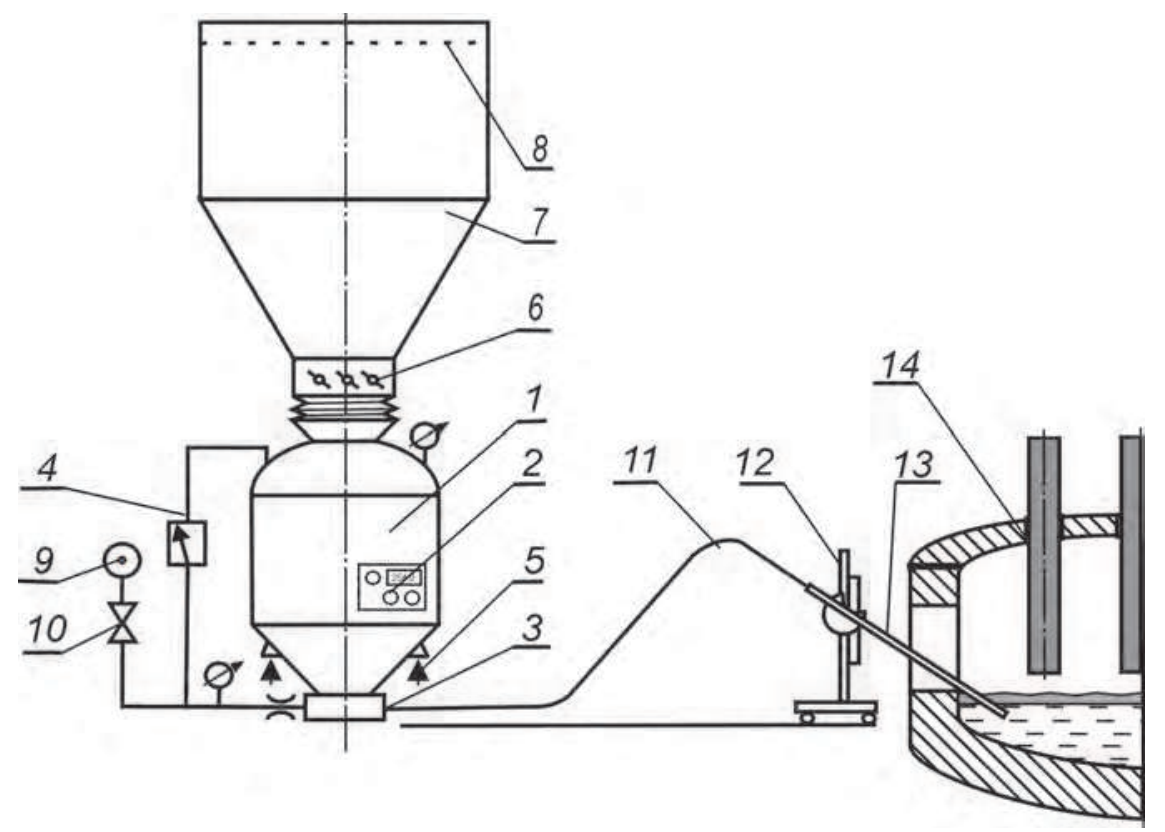

Fig. 1. The recarburization setup for the electric arc furnace: 1-pressure container, 2-control switchboard, 3-mixing chamber, 4-reducer, 5-extensometric scales, 6-slide damper, 7-silo, 8-screening sieve, 9-the compressed air supply, 10-main valve, 11-pipe, 12-lance manipulator, 13-injection lance, 14-electric arc furnace

For the surface carburizer addition in EAF the recarburization efficiency is at most around $53 \%$. It should be mentioned that such a result can be achieved only after tens of minutes because of very slow liquid metal movement inside furnace. The process can be accelerated by mechanical stirring but it is hard to do so. Very high efficiency level in EAF can be achieve with the use of pneumatic powdered carburizer injection. The $80 \%$ efficiency is recorded just after few minutes after the material has been completely introduced. Our researches have shown that the diphase stream parameters have strong influence on the efficiency and rate of the process (Janerka, 2010). These parameters depend on the feeders construction. Nowadays the devices allow the control of mass gas flow in the range from 0.03 to $0.20 \mathrm{~kg} / \mathrm{s}$. This parameter directly influences (when the geometry setup does not change) on the solid-gas velocity on the lance outlet and consequently on the stream dynamics. The particle velocity inside the pipe can be calculated as a product of the air velocity and carburizer particle slip coefficient in relation to carrier gas. This coefficient $\mathrm{s}$ is in range $s=0.5$ to 0.8 . Low gas flow causes low velocity and stream energy onto lance outlet and as a result the limited reaction zone between carburizer and liquid metal (small stream surface). Large carrier gas flow ensures good stream dynamics but simultaneously as a 
cooling effect significant liquid metal temperature decreases and more intense carbon oxidation occur (when the carrier gas is compressed air, larger oxygen amount is introduced). Too large carrier gas flow can cause a carburizer dozing decrease in some device designs. The material mass flow can be changed in range $m_{c}=0.10$ to $2.0 \mathrm{~kg} / \mathrm{s}$. Small device output increases recarburization efficiency but extends injection time what causes liquid metal temperature decrease. Large mass flow causes some carburizer portion not to be assimilated by liquid metal and floats into surface. It is an important recarburization process index, too. Of course, these two parameters mainly depend on furnace capacity which is directly related to the conveying pipe diameter. Badly chosen gas and material mass flow cause recarburization decrease to 40 to $50 \%$. Undoubtedly pneumatic recarburization in the electric arc furnaces is the only method to achieve high indexes of that process.

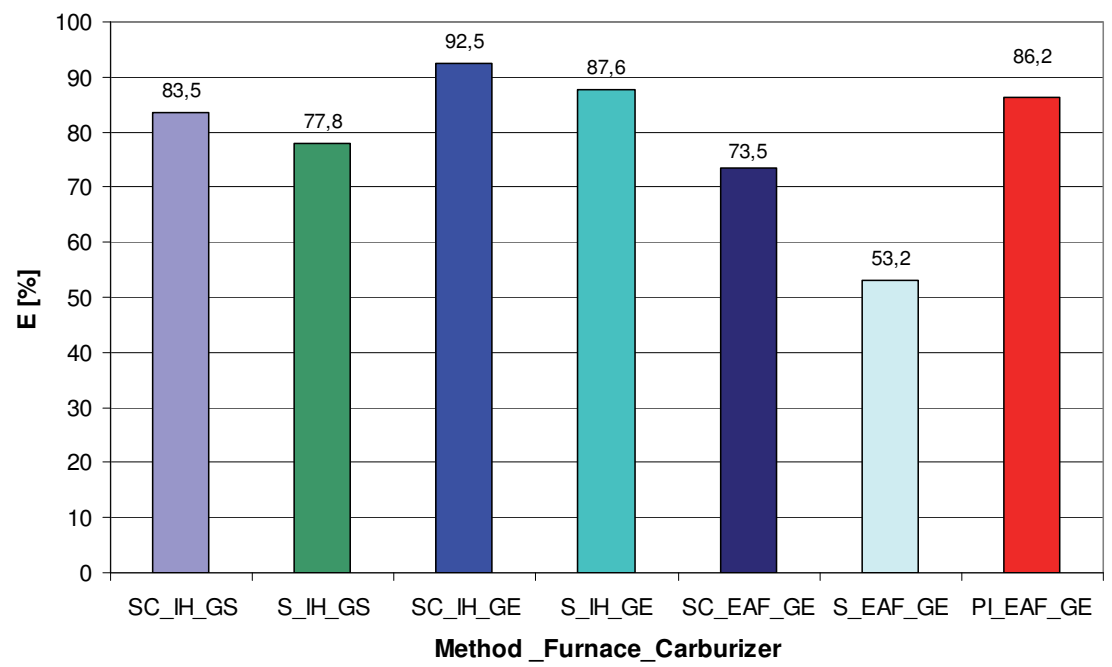

Fig. 2. The influence of recarburization method, furnace type and carburizer grade on the recarburization efficiency

\subsection{Powder and dust injection into cupola}

According to literature data (Ratkovic \& Dopp, 2004; Smyksy \& Holtzer, 2002, 2007) and authors' own experiences the cupola melting process creates dust in amount of between 4 $\mathrm{kg} / \mathrm{t}$ and $15 \mathrm{~kg} / \mathrm{t}$ of molten cast iron depending on the charging materials, furnace type and mass of cupola coke used (or not for coke-less cupolas). In Germany alone cupolas generate over $30000 \mathrm{t}$ of dust per year. The dust being sucked out includes many valuable elements which are additionally very harmful $(\mathrm{Zn}, \mathrm{Pb}, \mathrm{Cd})$. The Fe content is usually higher than $10 \%$, so the dust itself is a valuable charging material. When the dust contains $>15 \% \mathrm{C}$ it can be an extra fuel, too.

Since, nowadays a bigger and bigger part of the charge materials for cupolas (sometimes up to $40 \%$ ) comprises automotive scrap, mainly zinc coated sheets, the high $\mathrm{Zn}$ content in cupola dust appears a serious problem. The zinc content in the dust may achieve up to $20 \%$ what means it can be considered as a charge material in zinc metallurgical plants. Moreover, 
repeated recirculation of dust into the cupola causes an increase in the economic factors of the process.

At the Department of Foundry experiments of re-injection of cupola dust together with the finest fractions of ferrosilicon and anthracite (considered as wastes) were carried out and resulted in several industrial installations. The experiments were conducted with use of experimental setup built in the Department of Foundry and one of the most important results was industrial installation implemented in cast iron foundry, see Fig. 3 where its scheme was presented.

There are generally two methods of cupola dust treatment (when it is going to be re-used in furnace), the first is direct pneumatic injection back into furnace and the second is its briquetting and introduction into furnace in this form (Smyksy \& Holtzer, 2002). The Department of Foundry of Silesian University of Technology has been involved in the experiments of pneumatic dusts re-injection into cupolas for several years. Their effect, again with cooperation with POLKO company was designing and implementing of several installations that are described in the paper on the example of Czech foundry based on cupolas.

The mentioned foundry wanted to solve the problem of simultaneous injection of three materials of different characteristics:

- cupola dust,

- $\quad$ small fractions of FeSi (considered as wastes),

- pulverized anthracite.

Therefore the first step of experiments was developing the best mixture recipe both from metallurgical process (final carbon content in cast iron, impurities level etc.) and technological (pneumatic conveying parameters, estimated temperature drop etc.) point of view. Then the preliminary tests were carried out when the materials listed above and their mixtures: anthracite $+\mathrm{FeSi}(50 \%+50 \%$ mass $)$ and cupola dust $+\mathrm{FeSi}(50 \%+50 \%$ mass $)$ were used. The pneumatic injection installation was based on pneumatic chamber feeder of $V_{n}=$ $0.25 \mathrm{~m}^{3}$ capacity, see (Kanafek et al., 1999). The pneumatic chamber feeder was equipped with electronic control system and a precise dosing system within the required flow range $(2 \div 5 \mathrm{~kg} / \mathrm{min}$ ). The feeder's mass changes (during injection process) were continuously recorded with $\pm 0.1 \mathrm{~kg}$ accuracy which enabled to quickly estimate the powdered material outflow and in the same way the efficiency of the injection installation in the real time manner. Apart from the feeder, the installation consists of the elastic pipe of $L=25 \mathrm{~m}$ length and $\mathrm{d}_{\mathrm{w}}=0,025 \mathrm{~m}$ inside diameter from pneumatic feeder to the end of installation (injection lances integrated with cupola nozzles/tuyeres). Moreover, some important constructional changes in the mixing chamber (situated at the bottom part of the feeder, where the powdered material mixes with the carrier gas) were made. The porous liner to fluidize of loose material inside the container was situated at the bottom part of pneumatic feeder.

From the technological point of view not only pneumatic conveying parameters but the transportation stability during the injection cycle was crucial. After some design changes and parameters adjustment both results were achieved and for the powdered material mass flow $\mathrm{m}_{\mathrm{c}}=2 \div 5 \mathrm{~kg} / \mathrm{min}$ (well inside the requirements) the working cycle remained stable.

The implemented injection system integrated with cupola nozzles made utilization of the whole mass of dust from dust extraction system possible and the injection process did not negatively affect the produced alloy quality.

The implementation of the waste utilization method based on pneumatic injection in the aforementioned foundry enabled the recovery of waste materials received during 
metallurgical processes. Earlier this material was exported from the plant to special utilization facilities which was relatively expensive. The final economic indexes of the described foundry application were as follows:

- high decreasing of production costs about $20 \%$,

- increasing of the cupola effectiveness about $50 \%$,

- coke consumption decreasing about $10 \%$.

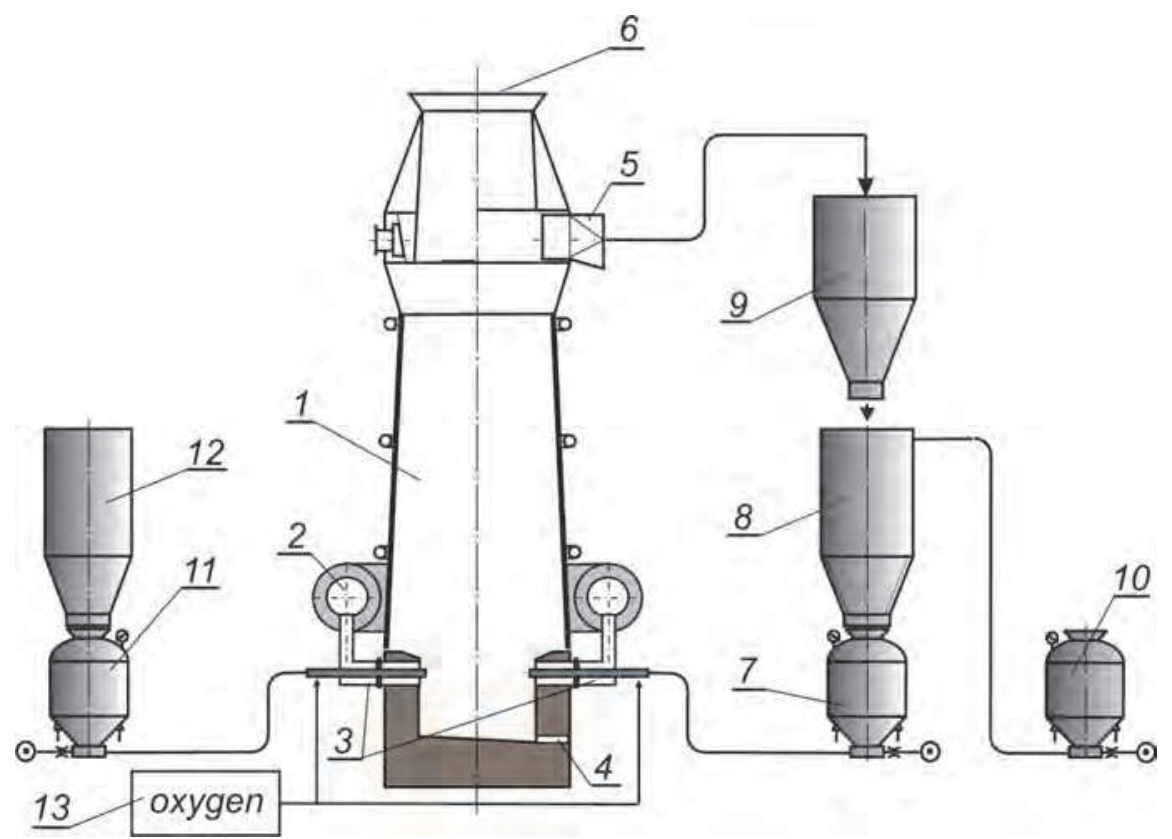

Fig. 3. Industrial cupola dust injection setup; 1- cupola, 2- wind box, 3-cupola nozzles (tuyeres), 4- tapping hole, 5- dust removal system, 6- charging door, 7- dust-coal mixture pneumatic chamber feeder, 8- dust-coal mixture container, 9- dust storage container, 10- coal pneumatic chamber feeder, 11- ferroalloys pneumatic chamber feeder, 12-ferroalloys storage container, 13- oxygen blow

\subsection{Metallurgical furnace dust injection for slag foaming}

One of the biggest problems in metallurgical and foundry industries is a large quantity of dust generated during production processes. The most important is furnace dust created when the molten metal is prepared and subsequently sucked out by the dust removal system (Machado et al., 2006, Ruiz et al., 2007; Vargas et al., 2006). At the Department of Foundry, the experiments with use of pneumatic injection method were carried out to utilize these kinds of materials and some results were successfully introduced into industrial applications. This part of the chapter shows that pneumatic injection technique could and should be continuously considered as an effective method for dust wastes utilization. The mass of dust generated during steel-making is enormous according to (Jezierski et al., 2008; Holtzer, 2005; Fiore et al. 2008). In Europe it is roughly 900000 t/year, in Japan over 450000 $\mathrm{t}$ /year and in Poland about $60000 \mathrm{t} /$ year. Over 30\% of total steel production is molten 
nowadays in electric arc furnaces (EAF) and one of the most significant environmental issues is utilization of dusts, often with high zinc content. Back in 1990s the experiments were started worldwide with dusts re-injection into melting furnace. The Department of Foundry of Silesian University of Technology a few years ago carried out the researches and then industrial implementation of the installation for dusts pneumatic injection back into 65 tons EAF in one of the Polish steel plants. The goal was to utilize the furnace dust in mixture with pulverized coal what should be good for slag foaming. The EAF's slag foaming method is well known and successfully used as a necessary approach for economical electrodes use, energy management and stability from the melting process point of view (electric arc stabilization). The scheme of the slag foaming process with use of pneumatic injection technique for reagent's mixtures introducing were presented in Fig. 4 below. The mixture of furnace dust and pulverized coal in the ratio of 3 to 1 was prepared. It was both due to chemical and technical reasons, firstly, to ensure estimated carbon content to start physical and chemical foaming reactions and secondarily to ensure fast and stable pneumatic conveying of the material through pipeline and finally injection lance. The furnace dust alone causes problems during pneumatic conveying and may suspend inside the feeder.

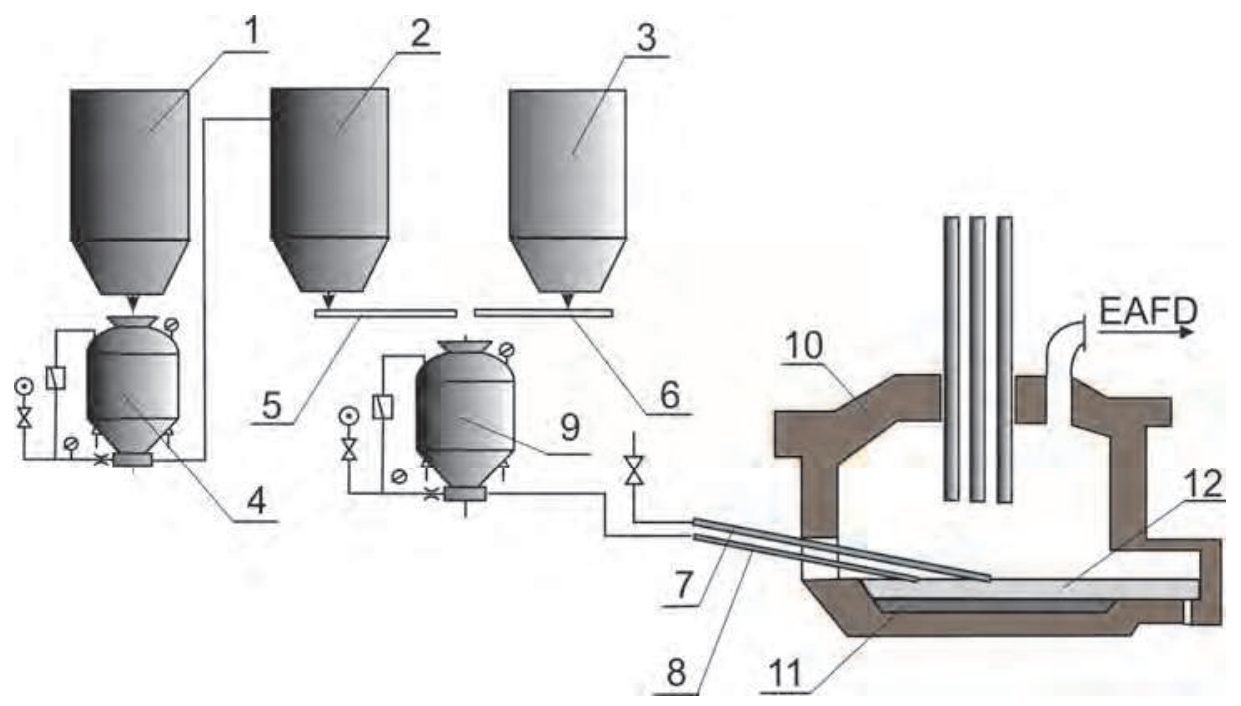

Fig. 4. The industrial set up for EAF dust-coal mixture pneumatic injection into 65 tons EAF: 1- furnace dust container (feeder), 2- intermediate dust container, 3- pulverized coal container, 4- furnace dust pneumatic chamber feeder, 5- dust feeding screw, 6- coal feeding screw, 7- oxygen lance, 8- mixture injection lance, 9- mixture pneumatic feeder, 10- EAF, 11- liquid metal, 12- expanded slag

The carrier gas (compressed air) was dried and the diphase gas-particles stream was created with use of the pneumatic feeder of own design (the former cooperation with POLKO company) and injection process started. The chemical composition of furnace dusts was typical for the steel plant which utilizes industrial scrap including automotive sheets with high zinc content. The researches were carried out firstly in laboratory conditions on the semi-industrial setup to estimate pneumatic conveying parameters for the material. After 
this stage the decision of producing a special chamber feeder design (with possible material fluidization) was made to ensure no material is suspended inside. Then the POLKO company (one of the best Polish companies in the pneumatic conveying field, formerly a part of the Department of Foundry) designed and manufactured the complete powder injection set-up: feeders, pipelines, automation and control devices etc. and the industrial experiments were started. During the industrial experiments a total of 278 melts were performed with various material compositions as follows:

- 167 melts with dust-coal mixture injection ( $90 \%$ of dust and $10 \%$ of powdered coal),

- 69 melts with dust-coal mixture injection ( $25 \%$ of coal and $75 \%$ of dust),

- 42 melts with the coal injection only (for comparison).

The main parameters of the process were:

- dust size: $0.005 \div 0.5 \mathrm{~mm}$,

- dust bulk density: $489 \mathrm{~kg} / \mathrm{m}^{3}$,

- coal grain size: $0 \div 3 \mathrm{~mm}$,

- coal bulk density: $667 \mathrm{~kg} / \mathrm{m}^{3}$,

- maximum mass of the mixture injected during one melt: $1330 \mathrm{~kg}$,

- mass composition of the mixture: $75 \%$ of dust $+25 \%$ of coal,

- mixture injection time: $10 \div 15 \mathrm{~min}$,

- $\quad$ system capacity: $0.5 \div 2.2 \mathrm{~kg} / \mathrm{s}$,

- unitary oxygen consumption: $2 \div 4 \mathrm{~m}^{3} / \mathrm{t}$,

- unitary dust consumption: $5 \div 11 \mathrm{~kg} / \mathrm{t}$,

- unitary coal consumption: $1 \div 3 \mathrm{~kg} / \mathrm{t}$.

The experiments proved high efficiency of the installation and after some minor parameters adjustments it was successfully commissioned and has been used till now. The energy consumption rate decreased significantly, the electrodes life extended and the process stability was improved, too. However, the most important result is that the plant utilizes all furnace dust generated by itself with several times less dust capacity deposited on dumps.

\section{Sand reclamation}

After the casting is knocked out the mould the used moulding and core sand become the by-products. The used sand can be utilized separately or with other components in the building industry, as a leak stopper on waste storage areas, as a material in concrete aggregate production and as a filler in a roads building industry. However, the important issue is to maximise utilization of used moulding sand by foundry plant itself by employing sand grains reclamation methods. The specific sand component recovery is a complex issue because the recovery alone is not enough to give the component the appropriate properties to use it again in new moulding sand preparation. The recovered components must meet quality requirements and be a fresh components replacement of full value (Danko, J., \& Danko, R., 2004; Danko J. et al., 2007; Danko R., 2004).

The sand reclamation process consists of following actions:

- preliminary mechanical impurities (metallic ones mainly) from the used sand separation,

- $\quad$ agglomerated sand break-up after casting knock out,

- screening and proper grain size fraction separation,

- repeated metallic inclusions separation process, 
- real sand reclamation, dry or wet, the goal is the residues of binding material removal out of sand matrix, with use of the methods which allow to remove thin material coating from the grain surface,

- sand matrix de-dusting or rinsing to remove all the unwanted reclamation products, proper grain size fraction of specific size and homogeneity separation (the classification on the grain size basis) (Szlumczyk 2005; Szlumczyk et al., 2007, 2008).

The field of sand reclaim application depends on the sand matrix grains cleanness degree that is binder from the grain surface removal and reclamation products classification. The essential reclamation process part is binder removal, that can be realized by abrasive sand matrix grains mutual reaction. The selection of the devices setup fitted for the reclamation process depends on the binder grade and the quality requirements for the reclamation products. The sand reclamation methods can be divided into wet and dry. In the second group the mechanical and pneumatic reclamation occur in the ambient temperature and thermal reclamation in the elevated temperature. In the wet reclamation method the used sand is mixed with water and in the form of pulp is mechanically treated usually in the rotary device. The sand grains are released not only from thin binder coatings and insoluble in water impurities but partly from insoluble impurities which can dispergate, too. The sand matrix after binder separation is rinsed, classified, dried and cooled.

In the mechanical method usually the machines are used which grind (mill), abrade or strike sand grains. In the pneumatic method which is a specific mechanical method modification, the binder layer removal is obtained by the collisions and abrasion of the sand grains in the air flow (cocurrently). In the pneumatic method the used sand conveying stream energy between technological appliances is employed. It is possible to insert the linear regenerator into straight segments of the installation which is purposely geometrically shaped (some throats are introduced) or on the pipe outlet to mount abrasive-percussive cap, which changes the stream direction. The controlled disturbance in pneumatic stream inside pipeline intensifies abrasive cleaning of the binder residues from matrix grains process. The movement of the pneumatically driven particles is defined by the resisting forces caused by gas and material friction on the pipeline's walls, particles friction on themselves and gravity and inertial forces of lifted particles. The reclamation process was carried out on the installation fitted to sand matrix pneumatic reclamation with the linear regenerator and abrasive-percussive cap (Szlumczyk 2005; Szlumczyk et al., 2007, 2008). The experimental reclamation setup consists of the following systems (Fig. 5):

- $\quad$ high-pressure pneumatic conveying chamber feeder (1),

- linear regenerator (3) cooperating with the pipeline of $D_{N}=0.08 \mathrm{~m}$ diameter,

- receiver (4) connected to de-dusting system,

- fluidized air classifier (6) which is a separate device,

- gas mass flow meter (5),

- $\quad$ abrasive-percussive cap as a receiver (7),

- controlling, measuring and regulating instruments.

The linear regenerator parts used in the experiments were shown in Fig. 6. They were made of wear resistant plastic and their shape corresponds to Witoszynski nozzle on inlet and Laval nozzle on outlet and such a shape was a result of model experiments described further in the paper. The analysis of the receiver (abrasive-percussive cap) influence on the binder coating removal (destroying) process correctness can be based on the maximum air flow rate. The cap was shown in Fig. 7. According to the stream theory and own research it can be assumed that for the distance between pipeline outlet point and abrasive-percussive 
cap up to $l_{1}=0.3 \mathrm{~m}$ the particles of $\mathrm{d}_{\mathrm{s}}>0.3 \mathrm{~mm}$ diameter, velocity does not change. To simplify: for the manufacturing method sake it was set up that the inner cap surface shape is a cylinder of $\mathrm{R}_{1}$ radius. On the basis of the experiments results as well as calculations it can be stated that the pneumatic sand matrix reclamation installation is suitable for the sand grades being examined. The effectiveness of the linear regenerator depends on compressed air supply system parameters what is essential to achieve proper diphase stream parameters. These parameters are transportation velocity and mixture mass concentration. The significant element of the proper process run is the constructional design of the throat. It is decisive for the resistance of flow. When the throat degree is small, the process efficiency decreases while for a too large one (over $S_{p}=4$ ) the resistance increases what makes it impossible to achieve better efficiency and more than one use of the throat elements on the sand matrix being reclaimed stream way. The carried out experiments indicated that the best results of the linear regenerator application were obtained for the flow of $\mathrm{w}_{8}$ velocity from 15 to $28 \mathrm{~m} / \mathrm{s}$ and $\mu_{\mathrm{m}}=12$ to $25 \mathrm{~kg} / \mathrm{kg}$ mixture mas concentration. In these conditions the system ensures good sand matrix reclamation process results for the moulding sand being processed. The use of the abrasive-percussive cap needs the diphase stream velocity on the pipeline inlet into cap adjusting.

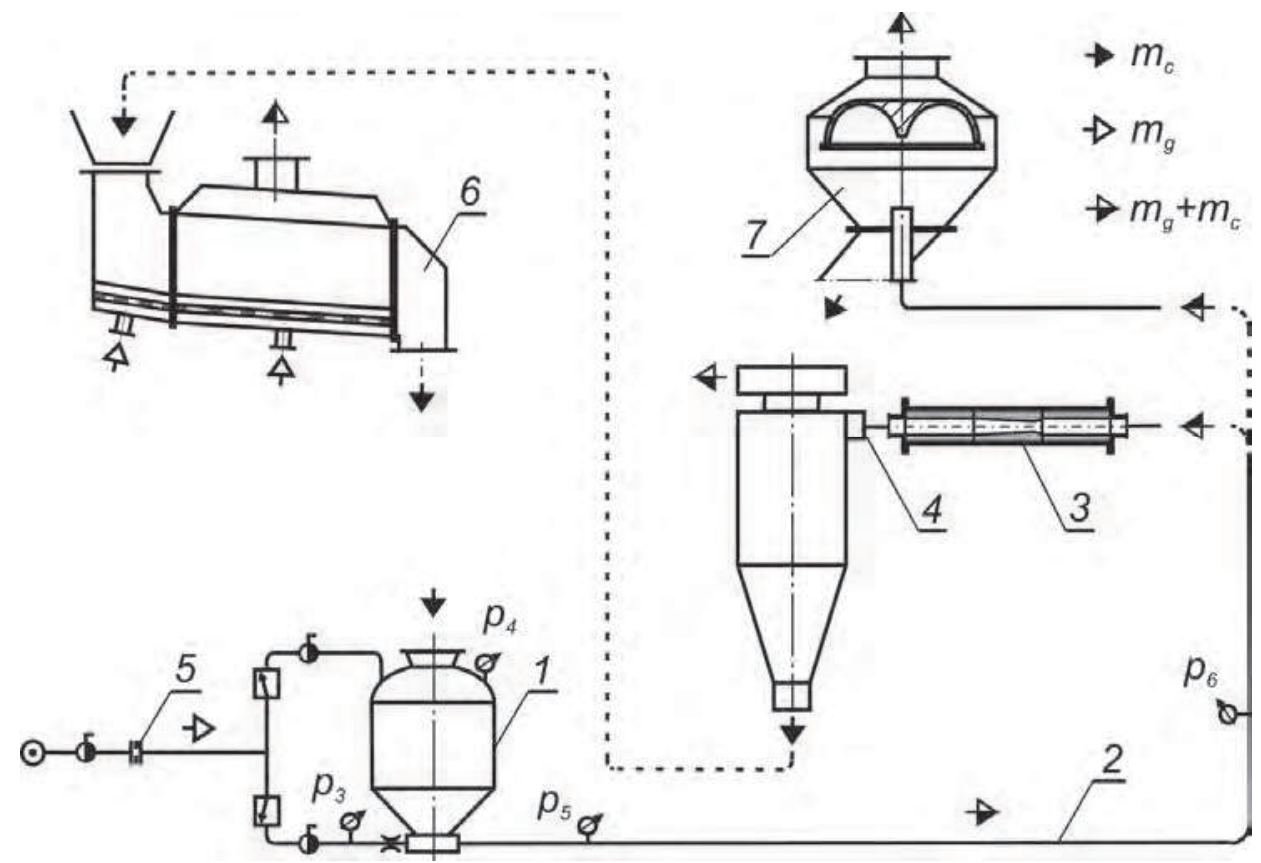

Fig. 5. The experimental setup scheme

The velocity should not exceed critical value what may cause sand matrix grains deterioration (cracking and scaling). The acceptable velocity of the stream introduced into cap $\mathrm{w}_{\mathrm{AN}}=35 \mathrm{~m} / \mathrm{s}$. When the effectiveness of these two pneumatic sand matrix reclamation systems is analysed, it can be stated that they are more beneficial than other dry reclamation systems. 

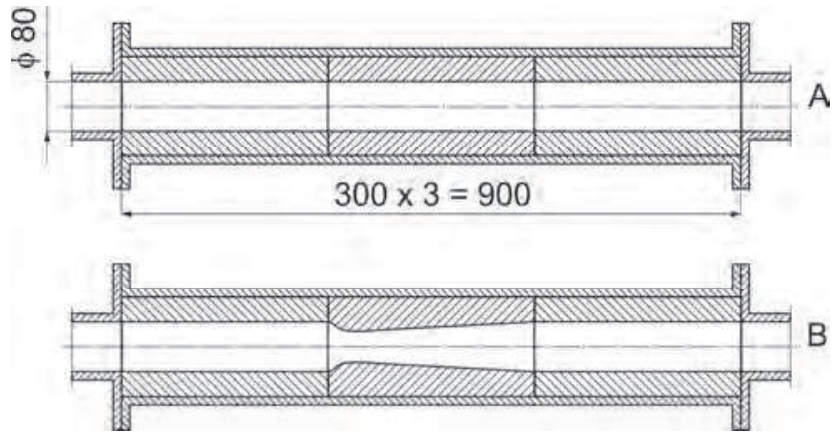

Fig. 6. The linear regenerator parts

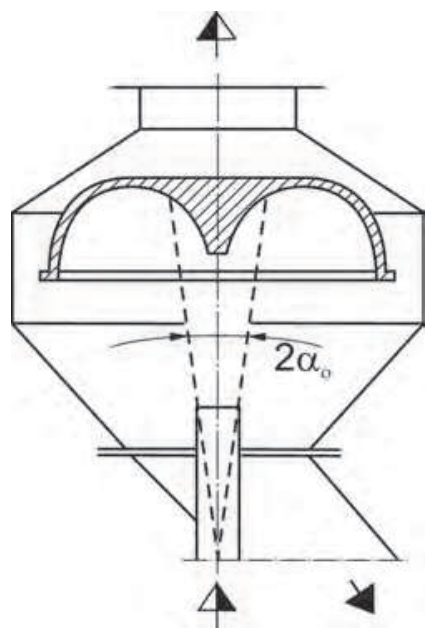

Fig. 7. The scheme of the stream on the abrasive-percussive cap surface influence process.

\section{Physical modelling of the powder injection process}

The observation of the diphase stream is often impossible. The conditions that limit direct observation are high liquid metal temperature (in powder injection into liquid metal process) or dustiness (in the sand reclamation process). Therefore physical modelling experiments are carried which allow to some extent to explain the phenomena visible in diphase stream conveying processes. The experiments on the models must be carried out with regard to the similarity theory otherwise the results cannot be transferred onto industrial installations and can be analysed in only exact research conditions. There are several similarity conditions description methods i.e. relationships between physical quantities scales which describe some phenomenon being examined. All of them are based on the dimensional analysis (Clift et al., 1978; Farias \& Irons, 1986; Sawda \& Itamura, 1989). Many authors dealt with the issue of the diphase stream (Szekely, 1979; Zhang, \& Fruehan, 1991; Zhao \&Irons, 1990). Most often the model experiments are conducted on the various liquids, gases and solids being introduced. The results estimated with the help of the criteria 
number are transferred on the liquid metal conditions. Increasingly, for analysis of these parameters, numerical modelling and computer simulation of the occurring phenomena is conducted after previous physical modelling of the powder injection into liquid process been made. During the observation of gas or gas and solid mixture flow introduced into the metal bath almost every scientist distinguished two flow states: bubbling (so-called barbotage) and jet flow. The first is characteristic for the small material mass flow and velocity on the lance outlet. The mass transport occurs only on bubbles surface, which are deformed and disintegrated just under the surface of the liquid medium where they are introduced. The second condition is characteristic for the big material mass flow and velocity on the lance outlet. The large bubbles deform and disintegrate just on the lance outlet that causes the large reaction surface between liquid and solid material being introduced. This condition is much more beneficial than the barbotage. For small injection velocity the bubbles break away the stream momentarily. When the velocity is higher the stream penetrates the liquid further and wrinkles and the small bubbles appear. The stream introduced into liquid causes the injected material with liquid mixing and the assimilated droplets transport the stream further. When the stream velocity increases the larger gas amount mixes with the liquid (Janerka et al., 2004).

The goal of the physical modelling is sometimes the introduced diphase stream surface estimation what is an area of the intense mass transport between solid reagent and metal bath and the stream penetration range. The aim of the experiments is to show what parameters and how significantly they influence the shape and size of the diphase stream area inside liquid medium. Such experiments are carried out on the special setups for the physical modelling. The example of the setup based on the high pressure pneumatic conveying chamber feeder is shown in Fig. 8. The material supplier is the pressure container (1) of $3.0 \mathrm{dm}^{3}$ capacity.

The closing valve is mounted at the top of the container. The overpressure inside the container which device efficiency is based on, is regulated by means of the reducing valve (7). The spring-type pressure gauges in particular setup places were mounted to measure the overpressure. The carrier gas supplying system consists of compressor (8), cut-off valve (9) and the reducer with filter (10). The gas flow meter (11) was used to gas flow measuring. The powders introducing systems contain pipes (12) ended with a lance (13) introduced into

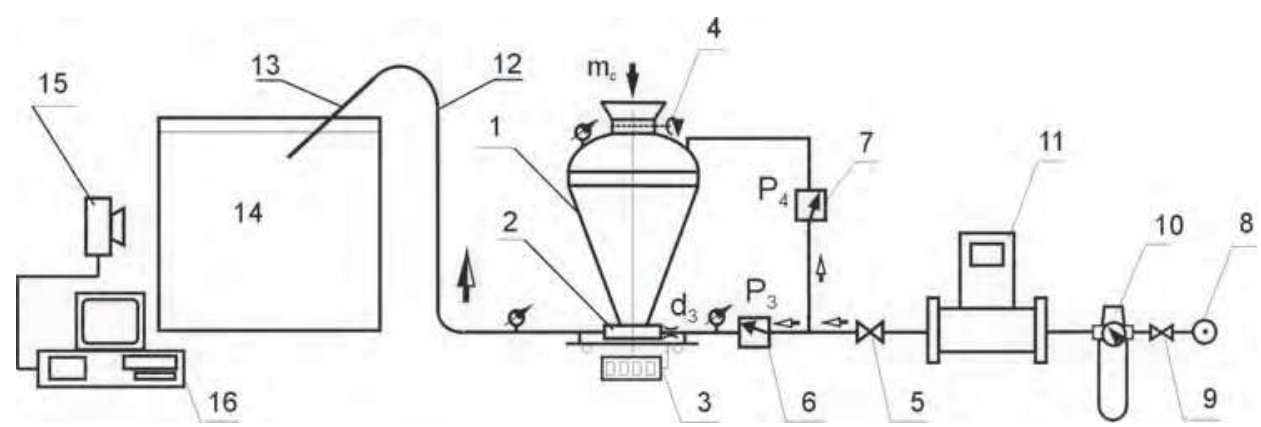

Fig. 8. The example setup for the physical modelling: 1-pressure container, 2-mixing chamber, 3-scales, 4-closing valve, 5,9-cut-off valves, 6,7-pressure reducers, 8-compressor or pressurized argon bottle, 10-carrier gas filter, 11-flow meter, 12-pipes, 13-injection lances, 14model liquid container, 15-digital camcorder or camera, 16-computer 
container (14) and made of Plexiglas (dimensions 1000x500x100mm). Every experiment is recorded on the digital camera (camcorder) and the captured pictures are transferred to the computer. As a model, powders of water insoluble materials are mostly used (plastics). Such experimental example with the use of polystyrene and polyethylene of $0.26-1.20 \mathrm{~mm}$ diameter was presented below. The injected materials density varied from $\rho=822 \div 1240$ $\mathrm{kg} / \mathrm{m}^{3}$. As a model, liquid water and water $\mathrm{NaCl}$ solution of $1180 \mathrm{~kg} / \mathrm{m}^{3}$ density were used. The injection process was carried out with the injection lance of $5 \mathrm{~mm}$ diameter and it was sloped at an angle of $\alpha=30,45,60^{\circ}$ to the liquid surface and submerged to depth $h=50$ and $100 \mathrm{~mm}$. The air only injection into liquid medium with various velocities was shown in Fig. 9 while in Fig. 10 next page the diphase stream injection with various parameters was presented.
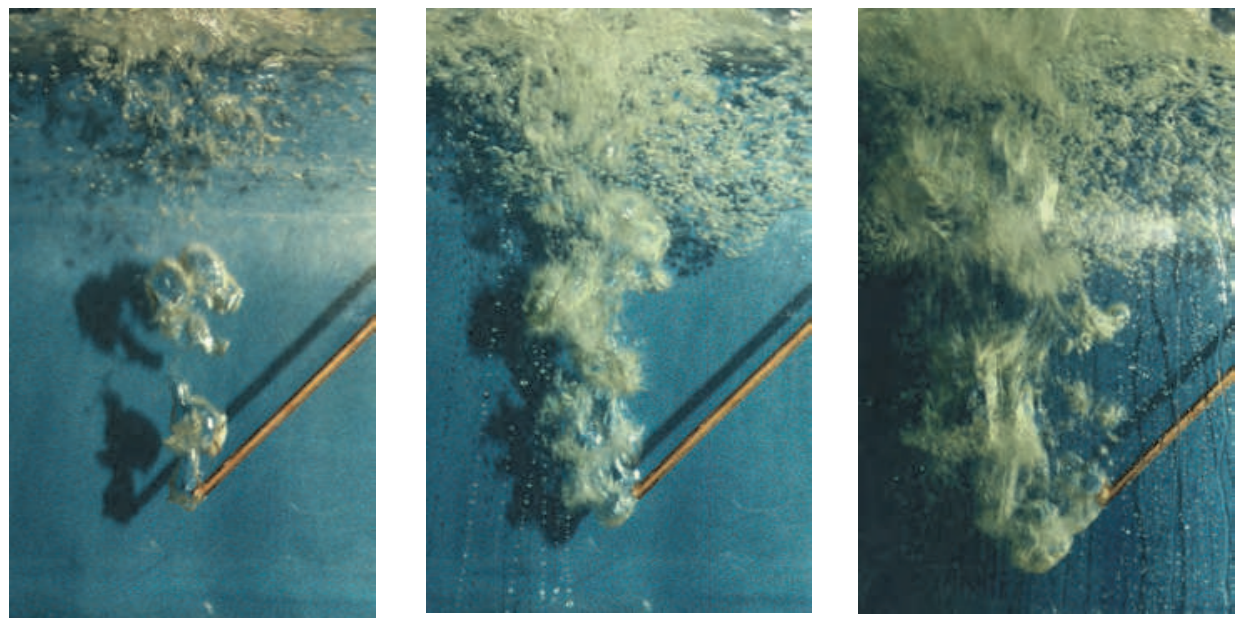

Fig. 9. The single phase (the air) injection into liquid medium with velocity of $w=6.8 \mathrm{~m} / \mathrm{s}$, $\mathrm{w}=37.1 \mathrm{~m} / \mathrm{s}$ and $\mathrm{w}=78.5 \mathrm{~m} / \mathrm{s}$

The single phase stream penetration range increases as the carrier gas mass flow increases. However, it is several times smaller than for the diphase stream injected under the same pneumatic conveying parameters. It is because the higher diphase stream energy is mainly kinetic. The diphase stream injection causes fewer disadvantageous phenomena appearance on the liquid surface (splatters). The higher stream penetration range is also obtained when small particles are introduced. It may occur because the smaller particles present higher velocity on the lance outlet and the liquid medium resistance for these particles is less. This is a good condition (from the process point of view) because smaller particles give larger extended surface of the injected powder for the same total volume of the injected particles. It results in higher technological indexes such efficiency and recarburization rate. However, fine powders of small density cause problems during pneumatic conveying because of their tendency to go into suspension inside chamber feeders and non-uniform falling down the container.

The diphase stream area can be divided into four characteristic zones (Fig. 11).

Zone I - close to the lance outlet. In this area large gas bubbles of irregular shape are created. Their size and number depend on gas flow. When the flow is higher, bubbles break 
away from the lance faster and faster disintegrate and again new bubbles are created. The carburizer particles are captured in them and after the bubbles burst they will have a contact with liquid metal. However, it occurs close to or even on the metal surface. The mass exchange takes place as a result of metal movement and carburizer grains floating on the metal surface. This is a disadvantageous phenomenon but it can be minimized with the gas velocity on the lance outlet increase.
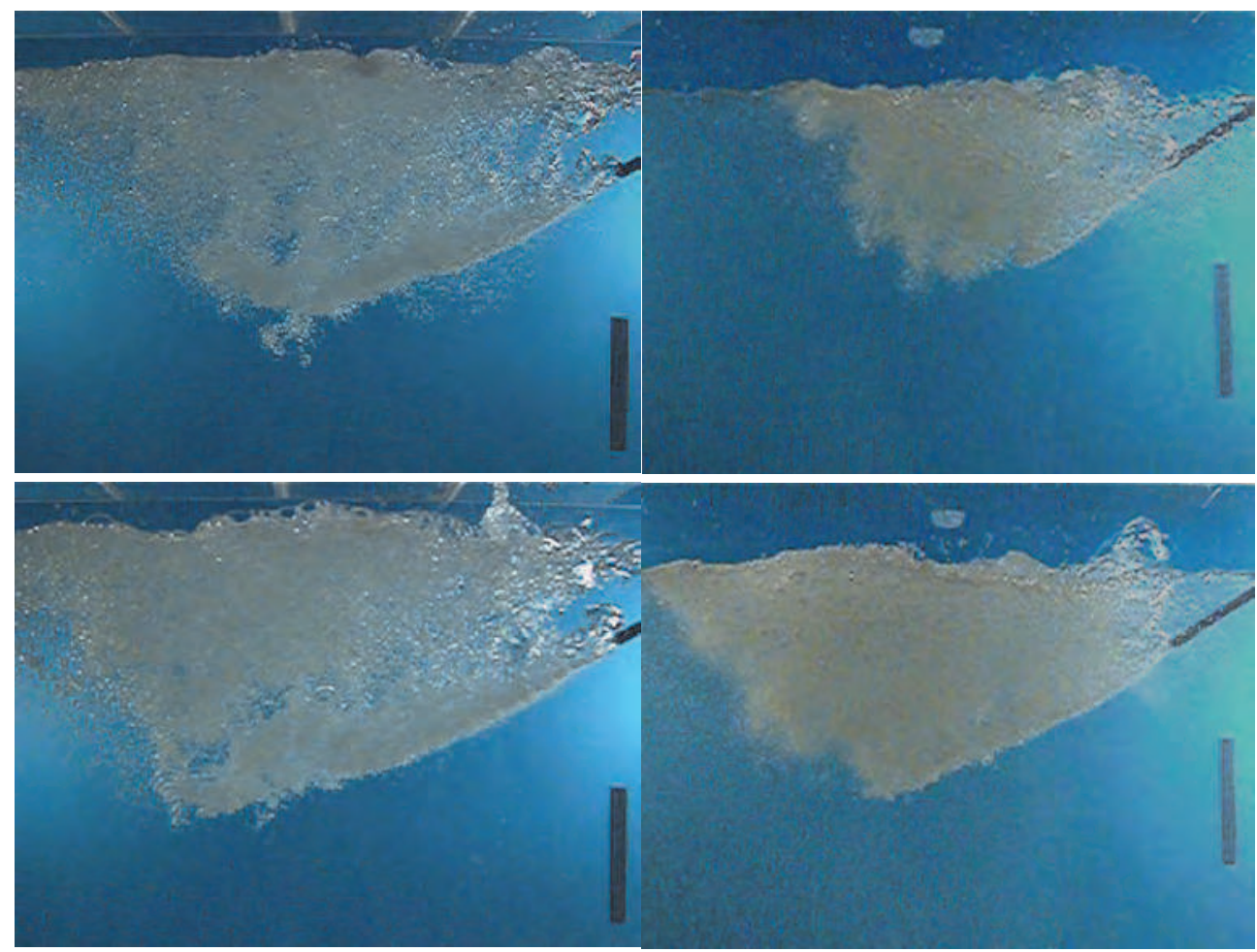

Fig. 10. The diphase stream injection for the particles of $d_{c}=0.833 \mathrm{~mm}$ diameter and $\rho=882$ $\mathrm{kg} / \mathrm{m}^{3}$ density, liquid density $\rho_{\text {osr }}=1000 \mathrm{~kg} / \mathrm{m}^{3}$ (left) and $\rho_{\text {osr }}=1180 \mathrm{~kg} / \mathrm{m}^{3}$ (right picture)

Zone II is a direct stream range area. It mainly consists of carburizer particles because only they have enough energy to infiltrate the liquid metal so deeply. The mass exchange process is the most intense in this zone because the particles have significant velocity so the nearsurface diffusive layer thickness is very small.

Zone III is the area of the smallest particles having direct contact with liquid metal. Its area is the largest and it may be assumed that it determines the process efficiency. The size of this zone is a consequence of zone II creation.

Zone IV consists of bubbles of spherical, ellipsoidal or spherical cap shape, dependably on the bubble creation place and its size. Moving towards the surface the hydrostatic pressure decreases what causes their growth. Being in liquid metal they heat themselves additionally and their volume increases. They burst close to or on metal surface so the particles are there 
partly uplifted. The carburizer particles are captured inside these bubbles and the mass exchange occurs after their bursting under the liquid metal surface what significantly decreases the process total efficiency.

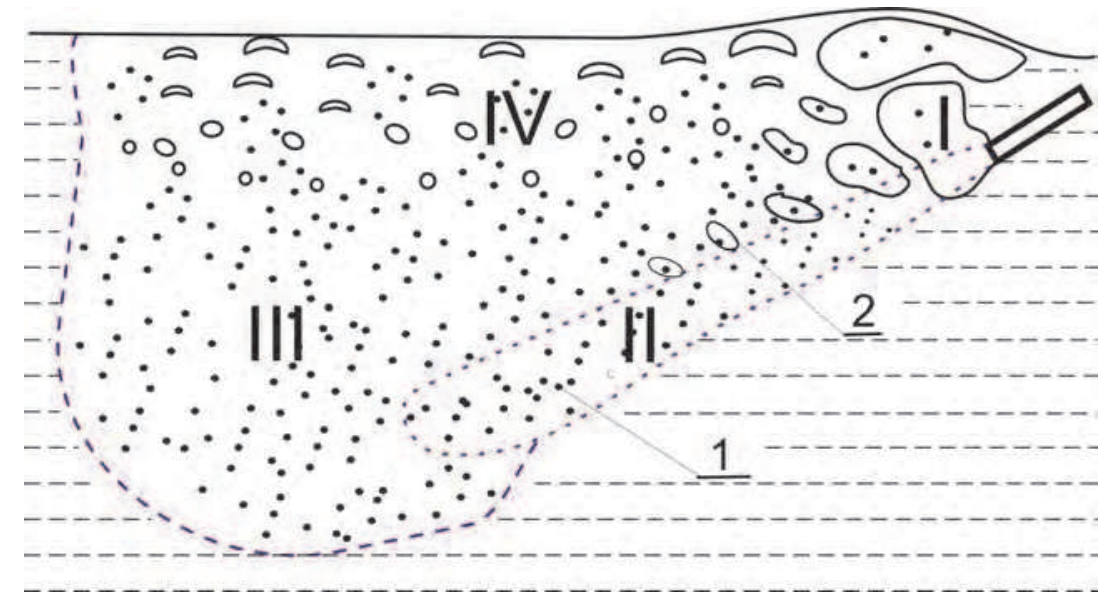

Fig. 11. The shape and area of the diphase stream: 1-carburizer particles, 2-gas bubbles

Under industrial conditions of pneumatic recarburization the estimated process efficiency is obtained thanks to overpressure and exchangeable nozzles in dosing device changes. It allows controlling gas flow as a one of the main parameters of pneumatic conveying process. The dosing device output increase is obtained mostly by increasing overpressure inside chamber feeder container. Subsequently the flow increase (mass gas and material flow) causes adequate surface area, width and penetration range of the diphase stream increase. The fine particles injection is very beneficial not only from metallurgical point of view (large contact surface between reacting phases) but because the more significant diphase stream surface and direct reaction zone metal-carburizer increase, too.

The model experiments were carried out to select the best geometrical layout of the throats used in the linear regenerator, too. The research consist of stream flow conditions analysis in various geometrical throat layouts inside pipe system. The aim was to force the flow instability that causes mutual particle interaction. During the experiments the stream flow of various mass concentration velocities and the pressure drop on the measured section of the pipe system were recorded. The particles distribution inside this stream was analysed.

These experiments were also recorded photographically. Typical photographs of the solid particles distribution inside diphase stream were presented in Fig. 12.

The model experiments were employed to optimize constructional setup of the throats in the linear regenerator and to estimate their shape (Witoszynski nozzle on the inlet and Laval nozzle in the outlet). These sections were made of transparent material (Plexiglas) to make particles movement observation during the diphase stream flow possible. The solid particles were granulated polypropylene ones of $2-3 \mathrm{~mm}$ size and black and white colours. The recordings and observations results allow analysing the diphase stream flow parameters inside the particular linear regenerator sections. The particles agglomerations are visible on the linear regenerator inlet (throat) what suggests their mutual interactions intensity increase with the small resistance of flow caused by differential pressure. 


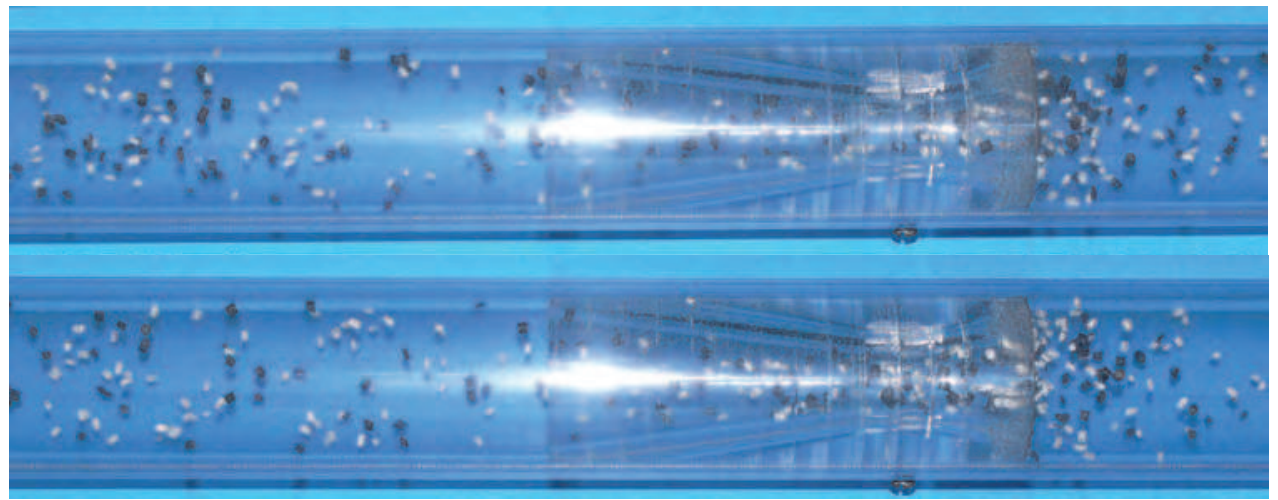

Fig. 12. The stream flow inside model linear regenerator system

\subsection{Diphase gas-particles stream force model analysis}

The experiments (as a continuation of the model experiments described above) were carried out to understand the character of diphase stream forces on liquid surface in powder injection process. The short description of work methodology and apparatus are mentioned in the paper as well as the examples of the results obtained. The work presented in the paper is a part of a large scaled experimental plan that should explain important relations between injection technological indexes and dynamics of the diphase stream. The research stand is presented on fig. and its complete description was presented in previously published paper (Jezierski et al. 2006) but instead of furnace or ladle a measuring device is situated at the end of the injection system and connected to PC computer, see Fig. 13.

The experiments were conducted as part of the experimental plan for various lances geometries, pneumatic parameters and injected powdered materials sorts. Use of PC computer with dedicated program allowed to measure stream force value with frequency 10 measurements per second. So we can say that the stream force measurement was almost continuous. The powdered material used in the experiment was polystyrene with granulation $0.4 \mathrm{~mm}$ with the air as a carrier gas. The distance between lance outlet and an extensometric measuring device's surface was established at three levels: 10, 40, 80mm because one of the problems to solve was that distance influences stream force's value achieved.

The full experimental plan included 27 experiments for various process parameters configurations separately made. Apart from a grain size there were four another independent variables during experiments:

- a carrier gas (compressed air) pressure $\mathrm{p}_{1}$, (three levels of changing: $0.1 ; 0.2 ; 0.3 \mathrm{MPa}$ ),

- a gas into dispenser pressure $\mathrm{p}_{4}$ (six levels of changing: from 0.05 to $0.3 \mathrm{MPa}$ with step $0.05 \mathrm{MPa})$,

- a distance between lance outlet and measuring device surface $H(10,40$ and $80 \mathrm{~mm})$,

- $\quad$ a lance inside diameter $d_{w}$, (three levels of changing: 5.6; 6.1 and 7.6mm).

The results of the recordings and calculations were used to analyze and to create the graphs to show time-changing character of stream force. The examples of the graphs for experiments with use of lance with inside diameter $6.1 \mathrm{~mm}$ were presented below in Fig. 14 . One can see a characteristic peak at the end of the blowing. It is connected to moment when the last portion of mixture is blown through the injection lance. From technological point of 
view the most important is the period when force stabilizes in the middle of the cycle because in real industrial conditions we are interested mainly in the process stability. When one looks precisely at graphs one can see that for some combination of pneumatic parameters $\mathrm{p}_{1}$ and $\mathrm{p}_{4}$ quite considerable stream force fluctuations can be seen. It is mostly present in cases when the pressure into container (above powdered material) $\mathrm{p}_{4}$ has value from the highest levels equal 0.25 or $0.3 \mathrm{MPa}$ and carrier gas pressure $\mathrm{p}_{1}$ has the smallest value equal $0.1 \mathrm{MPa}$ (Fig. 15 next page). In such conditions for small lance's inside diameter the mass concentration of diphase mixture value is too big so the pneumatic conveying character seems to be pulsating not stable.

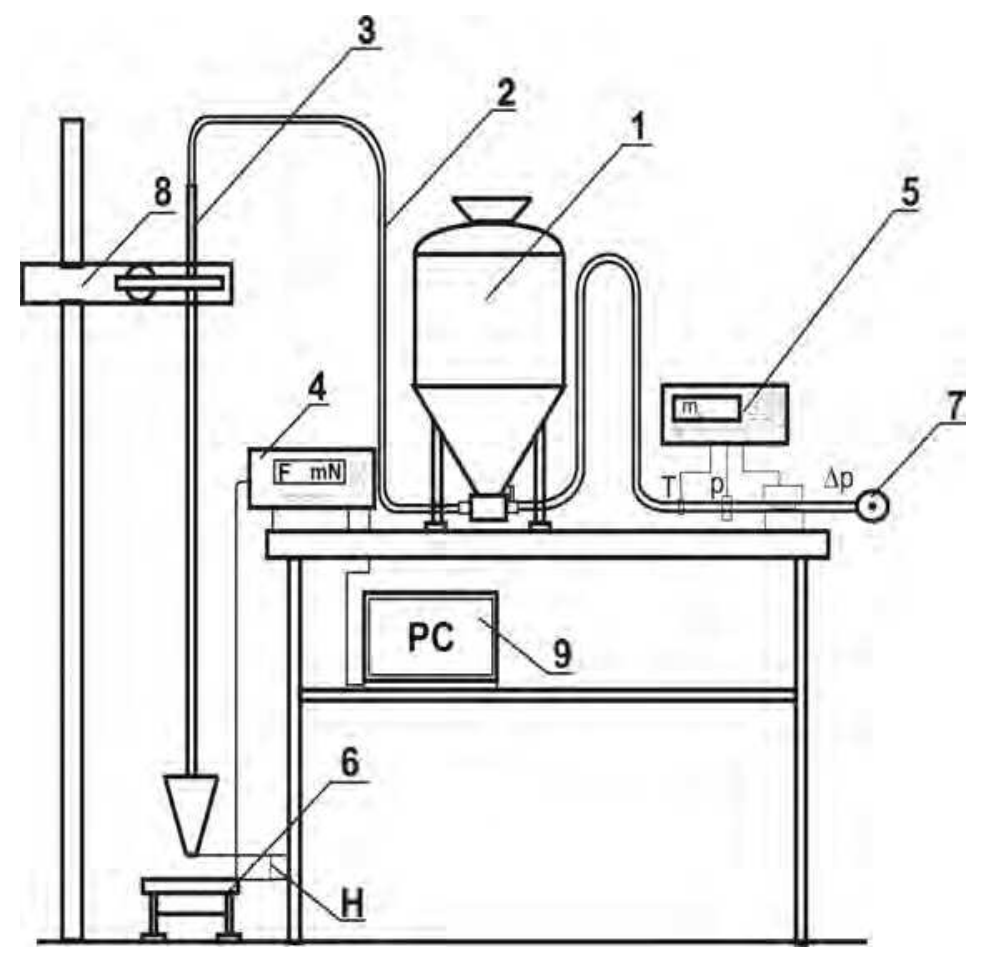

Fig. 13. Scheme of research setup; 1- pneumatic powder chamber feeder, 2- pipeline, 3-injection lance of special design, 4- stream force measuring electronic device, 5- carrier gas flow meter, 6- extensometric device, 7-carrier gas (compressed air) supply, 8- slidable arm, 9- PC computer, $\mathrm{H}$ - changeable distance between lance outlet and measuring device

The paper presents graphs for only one chosen inside diameter lance $d_{w}=6.1 \mathrm{~mm}$ but the described problems and relationships between process parameters were present in others examined lances, too. The fluctuations of force values were the biggest with use of the smallest lance of $5.6 \mathrm{~mm}$ diameter and the most stable process was observed for the lance of $7.6 \mathrm{~mm}$ inside diameter.

The next step was statistical analysis of recorded and calculated data. The average value of stream force in stable (during the stable cycle period) was calculated, the experimental equations were formulated and graphs were made. Below are presented some of them for 
the parameters analogical to these on the stream force's time-changing graphs, see Fig. 16 and 17 next pages.

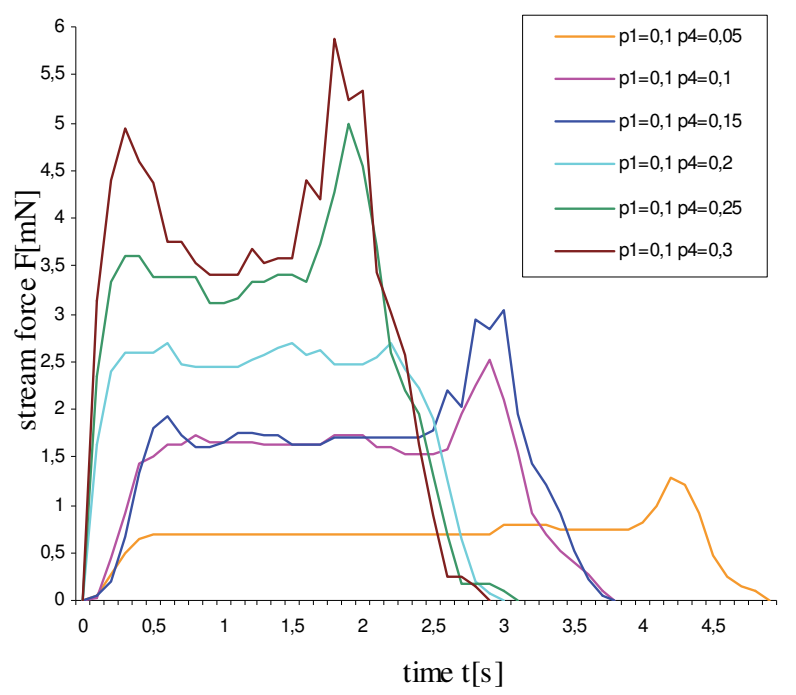

Fig. 14. Diphase stream force character for parameters as follows: lance diameter $\mathrm{d}_{\mathrm{w}}=6.1 \mathrm{~mm}$, distance between lance outlet and measuring device's surface $\mathrm{H}=40 \mathrm{~mm}$, carrier gas pressure $\mathrm{p}_{1}=0.1 \mathrm{MPa}$, powdered material - polyethylene of granulation $0.4 \mathrm{~mm}$

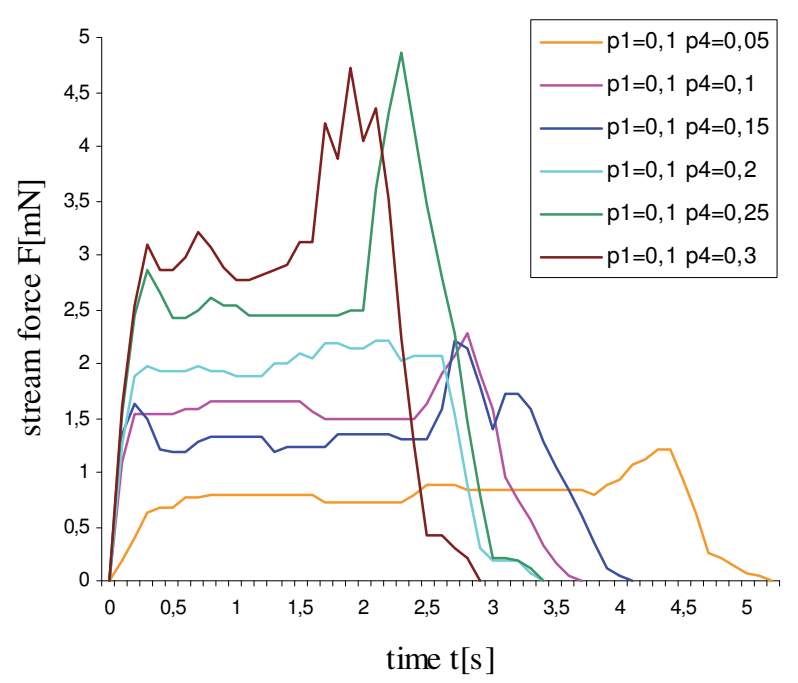

Fig. 15. Diphase stream force character for parameters as follows: lance diameter $\mathrm{d}_{\mathrm{w}}=6.1 \mathrm{~mm}$, distance between lance outlet and measuring device's surface $\mathrm{H}=80 \mathrm{~mm}$, carrier gas pressure $\mathrm{p}_{1}=0.1 \mathrm{MPa}$, powdered material - polyethylene of granulation $0.4 \mathrm{~mm}$ 


$$
\mathrm{F}=-0,785+0,032 \cdot \mathrm{w}_{\mathrm{k}}+0,019 \cdot \mu
$$

where: $\mathrm{w}_{\mathrm{k}}$ - gas velocity, $\mu$ - mass mixture concentration.

The described experiments have drawn to the following conclusions:

1. Velocity of the carrier gas in the lance outlet depends mostly (the same geometrical conditions) on inside lance diameter and mostly influence diphase stream force value.

2. Diphase stream force value increases with increasing pressures (especially pressure in powder feeder $\mathrm{p}_{4}$ which increase cause mass concentration $\mu$ increasing) and decreases with increasing of distance between lance outlet and measuring surface (liquid metal bath). For distances above $40 \mathrm{~mm}$ the value was so small that it was impossible to measure with used equipment.

3. The proper period of injection cycle for industrial conditions is in the middle of the process, when the stream force has good stability. The moment which show the finish peak introduced quite considerable amount of carrier gas with last portion of powder injected.

4. Mass concentration of the diphase mixture and velocity of carrier gas in the lance outlet have decisive influence on the analyzed force. But the value of $\mu$ should not be above $20-30 \mathrm{~kg} / \mathrm{kg}$ because the higher values cause high instability of conveying process.

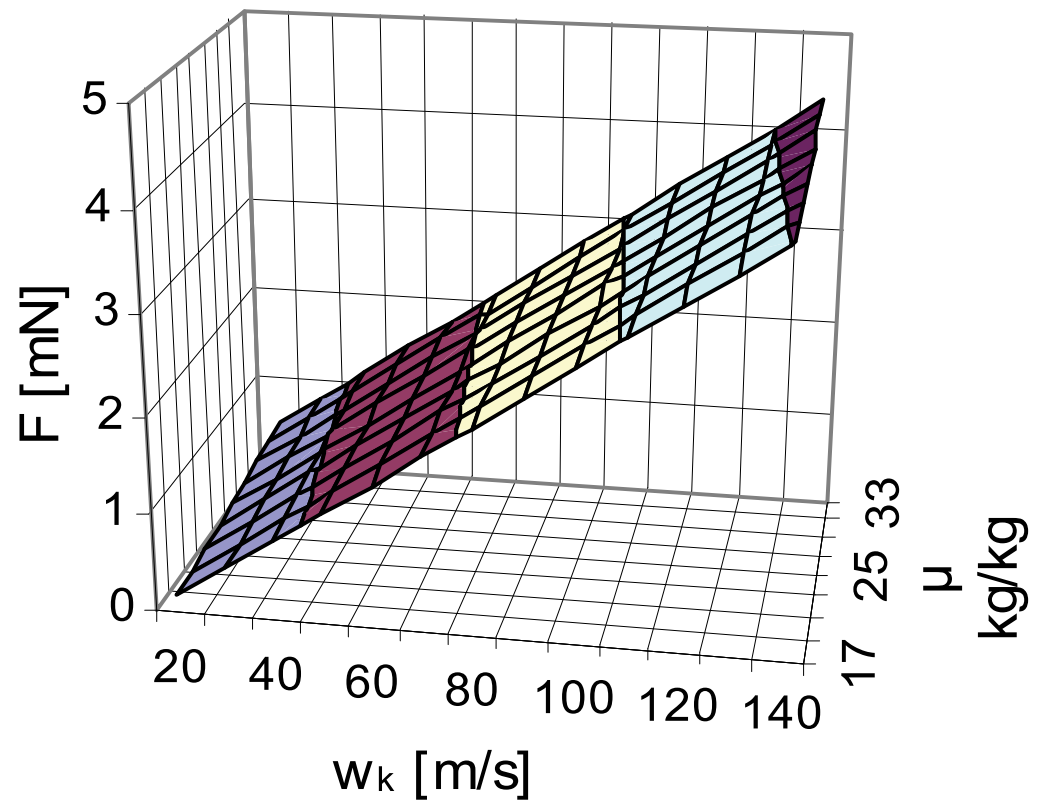

Fig. 16. Influence of gas velocity in lance outlet and mass concentration on the stream force $\left(\mathrm{d}_{\mathrm{w}}=6.1 \mathrm{~mm}, \mathrm{H}=10 \mathrm{~mm}\right)$

The further model experiments were carried out with the liquid medium and they proved the previously made researches without liquid usage. The stream force value corresponds strongly with the ability of the stream to infiltrate the liquid with the high stream penetration range. 
Below (fig. 17) there is shown a dependence between diphase stream force and pressure values.

$$
\mathrm{F}=-0,063+0,809 \cdot \mathrm{p}_{1}^{2}+1,831 \cdot \mathrm{p}_{4}^{2}
$$

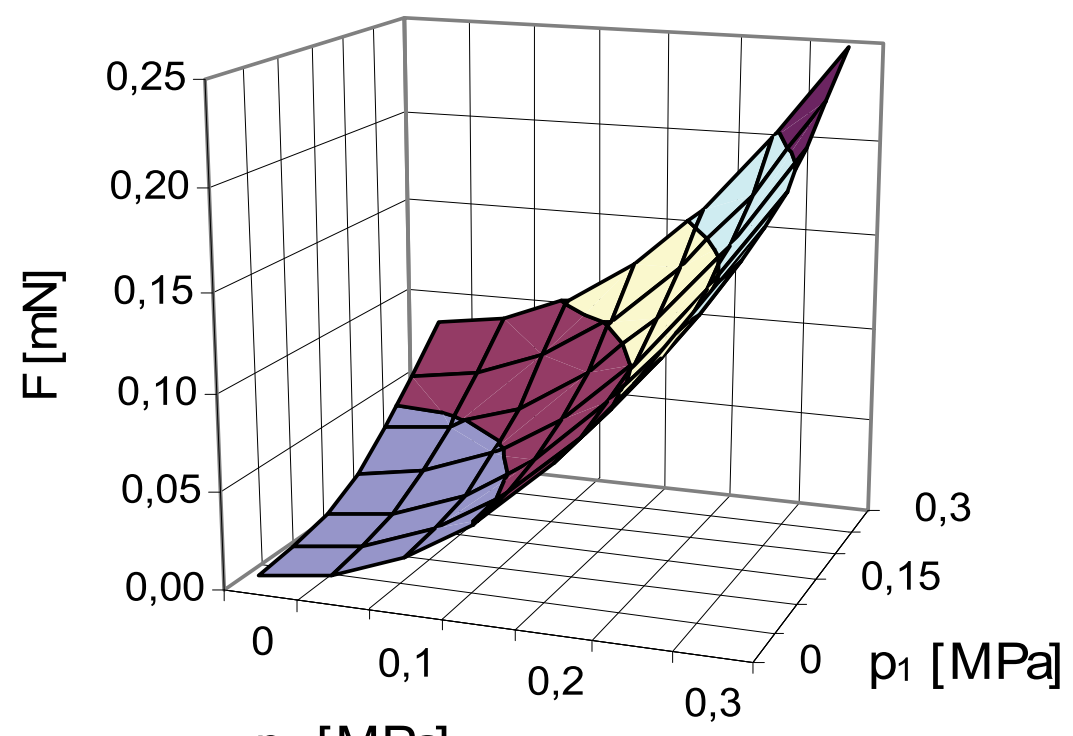

$\mathrm{p}_{4}[\mathrm{MPa}]$

Fig. 17. Pressure $p_{1}$ and $p_{4}$ values influence the stream force $\left(d_{w}=6.1 \mathrm{~mm}, H=10 \mathrm{~mm}\right)$.

\section{Conclusions}

In the chapter the usage of pneumatic powder injection method for solid metallurgical and foundry wastes mainly in form of powder or dust utilization was briefly presented. The experiments in this field have been made in the Department of Foundry, Silesian University of Technology for many years. These several experimental examples as well as industrial applications show how this technique can be employed to utilize furnace dusts generated in various kinds of furnaces, fine ferroalloys fractions (by-product of lumpy ferroalloys production) into liquid metal bath introduction, liquid ferrous alloys (mostly cast iron) recarburization and used moulding sand reclamation (pneumatic method). The results of author's experiments proved the high effectiveness of this method in every of the mentioned processes. The ecological and economic parameters of industrial application are very promising so the interest of the industry continuously increases. It seems to appear especially significant nowadays when environmental protection is one of the most important problems and when pollution limits are very low, too.

To develop further the theory of diphase stream movement and its characteristic inside liquid medium from the powder injection process point of view the next researches have been just launched. Their goal is to examine stream flow with use of the high speed camera 
to catch the real particular powder particle movement. Both model experiments and real injections into liquid metal are planned to observe how the gas-powder stream really enters the liquid metal surface. It will be the first such approach to the pneumatic powder injection process and the results of the experiments will be published later.

\section{Acknowledgements}

This research project was financed from support funds for science during 2010-2013.

\section{References}

Chojecki, A., Smetek, T. \& Hawranek, R., (2002). Technical and economic aspects of the cast iron recarburization in electric arc furnace. Foundry Review, No. 11, (November, 2002), pp. 361-369, ISSN 0033-2275

Cholewa, M., (2008). Selected Casting Processes, Silesian University of Technology, ISBN 978837-3355-36-1, Gliwice, Poland

Clift, R., Grace, J.R., \& Weber, M.E. (1978). Bubbles, Drops and Particles, Academic Press Inc., ISBN 978-082-4703-80-6, USA

Danko, J., \& Danko, R. (2004). Reclaim ability of used self-setting sand with selected type of resin. Archives of Foundry, Vol. 4, No. 13, pp. 45-50, ISSN 1642-5308

Danko, J., Danko, R., \& Lucarz, M. (2007). The processes and devices for the used sand matrix reclamation, Akapit, ISBN 978-83-60958-03-2, Cracow, Poland

Danko, R. (2004). Examinations of energy consuming of reclamation of used foundry sands. Archives of Foundry, Vol. 4, No. 13, pp. 51-56, ISSN 1642-5308

Engh, T.A., \& Larsen, K.: (1979). Penetration of particle-gas jets into liquids. Ironmaking and Steelmaking, No. 6, pp. 268-273, ISSN 0301-9233

Fiore, S., Chiara Zanetti, M., \& Ruffino, B. (2008). Waste Characterization in Steel Casting and Recycling Opportunities in Europe. American Journal of Applied Science, Vol. 5, No. 5, pp. 512-518, ISSN 1546-9239

Fu, P., \& Zhang, Q. (2008). Investigation on steelmaking dust recycling and iron oxide red preparing. Journal of University of Science and Technology Beijing, Vol. 15, No. 1, (February, 2008), pp. 24-28, ISSN 1005-8850

Holtzer, M. (Ed.), (2005). The guide for the best available techniques (BAT). The guidelines for the foundry industry, Ministry of the Environment, Warsaw, Poland

Holtzer, M., Niesler, M., Podrzucki, C., \& Rupniewski, M. (2006). Using cupola for recycling foundry dusts. Archives of Foundry, Vol. 6, No. 20, pp. 111-121, ISSN 1897-3310

Holtzer, M. (2007). Influence of the cast iron melting processes on environment using BAT. Archives of Foundry Engineering, Vol. 7, No. 4, pp. 83-88, ISSN 1897-3310

Farias, L.R., \& Irons, G.A., (1986). A Multi-Phase Model for Plumes in Powder Injection Refining Processes. Metallurgical Transactions B, Vol. 17B, No. 4, (March, 1986), pp. 77-85, ISSN 1879-1395

Janerka, K., \& Jezierski, J. (2002). The diphase stream appearance in powder injection into liquid process. Archives of Foundry, No. 5, pp. 74-79, ISSN 1897-3310

Janerka, K. (2003). The pneumatic injection parameters and particles properties influence on the stream penetration range. Archives of Foundry, No. 9, pp. 252-259, ISSN 18973310 
Janerka, K., Gawronski, J., \& Jezierski, J. (2004). The diphase stream surface in the powder injection process. Archives of Foundry, No. 14, pp. 189-196, ISSN 1897-3310

Janerka, K., Bartocha, D., \& Szajnar, J. (2009). Quality of carburizers and its influence on recarburization process. Archives of Foundry Engineering, Vol. 9, No. 3, pp. 249-254, ISSN 1897-3310

Janerka, K. (2010). The recarburization of the ferrous alloys, Silesian University of Technology, ISBN 978-83-7335-704-4, Gliwice, Poland

Janerka, K, Bartocha, D, Szajnar, J, \& Jezierski, J. (2010). The carburizer influence on the crystallization process and the microstructure of synthetic cast iron. Archives of Metallurgy and Materials, Vol. 5, Issue 3, (October, 2010), pp. 851-859, ISSN

Jezierski, J., Janerka, K., \& Szajnar, J. (2006). Powder injection into liquid alloys as a tool for its quality improving. Archives of Foundry, Vol. 6, No. 18, pp. 535-540, ISSN 18973310

Jezierski, J., \& Janerka, K. (2008). Pneumatic powder injection technique as a tool for waste utilization. International Journal of Environment and Waste Management, Vol. 6, No. 2, pp. 636-646, ISSN 1478-9876

Jezierski, J., \& Janerka, K. (2011). Selected aspects of metallurgical and foundry furnace dust utilization. Polish Journal of Environmental Studies, Vol. 20, No. 1, (January, 2011), pp. 101-105, ISSN 1230-1485

Kanafek, M., Homa, D., \& Janerka K. (1999). The cast iron recarburization in Teksid Poland S.A. foundry with use of the POLKO pneumatic system, Foundry Review, No. 7, (July, 1999), pp. 271-273, ISSN 0033-2275

Kokoszka, J., Markowski, J., Janerka, K., Jezierski, J., Homa, D., \& Chmielorz, W. (1999). Pneumatic cast iron recarburization in WSK "PZL-Rzeszow" S.A. Solidification of Metals and Alloys, No. 41, pp. 53-58, ISSN 1897-3310

Kosowski, A. (1982). The kinetics of the cast iron recarburization in induction furnace, Foundry Review, No. 1-3, (January-March, 1982), pp. 11-14, ISSN 0033-2275

Lee, G. S., \& Song, Y. J. (2007). Recycling EAF dust by heat treatment with PVC. Minerals Engineering, No. 20, pp. 739-746, ISSN 0892-6875

Machado, J. G. M. S., Brehm, F. A., Moraes, C. A. M., Santos, C. A., \& Vilela, A. C. F. (2006). Characterization Study of Electric Arc Furnace Dust Phases. Materials Research, Vol. 9, No. 1, pp. 41-45, ISSN 1516-1439

Przeworski, S. (1986). The evaluation of the selected carburizers suitability for the grey cast iron production in electric arc furnaces. Transactions of Foundry Research Institute, ( 1986), pp. 219-234, ISSN 1899-2439

Ratkowic, S., \& Dopp, R. (2004). Einblasen von Stauben in den Kupolofen. Archives of Foundry, Vol. 13, No. 4, pp. 193-200, ISSN 1897-3310

Ruiz, O., Clemente, C., Alonso, M., \& Alguacil, J. (2007). Recycling of an electric arc furnace flue dust to obtain high grade ZnO. Journal of Hazardous Materials, No. 141, pp. 3336, ISSN 0304-3894

Salihoglu, G., Pinarli, V., Salihoglu, N. K., \& Karaca, G. (2007). Properties of steel foundry electric arc furnace dust solidified/stabilized with Portland cement. Journal of Environmental Management, No. 85, pp. 190-197, ISSN 0301-4797

Sawda, I., \& Itamura, T. (1989). The mathematical modelling of the coupled reactions in the pre-treatment of molten iron by powder injection. Proceedings of the International Conference SCANINJECT, ISBN, Lulea, Sweden, 1989 
Skoczkowski, K. (1998). The carbon-graphite linings, The Wojciech Swietoslawski's Foundation for the Science and Science Potential Support, ISBN 838-757-635-2, Gliwice, Poland

Smyksy, K., \& Holtzer M. (2002). Possibilities of briquetting process using for cupola dust utilization. Archives of Foundry, Vol. 2, No. 3, pp. 121-128, ISSN 1897-3310

Szekely, J., Lehner, T., \& Chang C.W. (1979). Flow phenomena mixing and mass transfer in argon stirred ladles. Ironmaking and Steelmaking, No. 6, pp. 285-293, ISSN 0301-9233

Szlumczyk, H. (2005). Analysis of diphase stream in the linear regenerator. Archives of Foundry, Vol. 5, No. 15, pp. 387-396, ISSN 1897-3310

Szlumczyk, H., Janerka, K., Homa, D., \& Myszor, A. (2007). Pneumatic moulding sand reclamation in the linear regenerator system. Archives of Foundry Engineering, Vol. 7, No. 2, (June, 2007), pp. 53-56, ISSN 1897-3310

Szlumczyk, H., Janerka, K., \& Szajnar, J. (2008). Analysis of the processes in pneumatic moulding sand reclamation. Archives of Foundry Engineering, Vol. 8, No. 2, (June, 2008), pp. 137-140, ISSN 1897-3310

Vargas, A. S., Masuero, A. B., \& Vilela, A. C. F. (2006). Investigations on the use of electricarc furnace dust (EAFD) in Pozzolan-modified Portland cement I (MP) pastes. Cement and Concrete Research, No. 36, pp. 1833-1841, ISSN 0008-8846

Zhang, X.D., \& Fruehan, R.J. (1991). Modelling of gas stirring in electric arc furnaces experimental results of physical modelling. Electric Furnace Conference Proceedings, ISBN 214-348-0643, Dallas, USA, 1991

Zhao, Y.F., \& Irons G.A. (1990). The breakup of bubbles into jets during submerged gas injection. Metallurgical Transactions B, No. 21B, (December, 1990), pp. 997-1003 , ISSN 1073-5615 


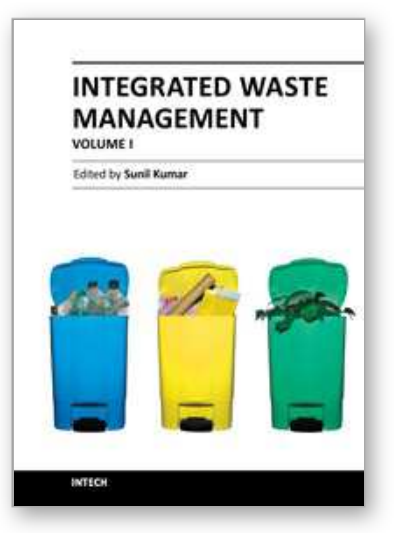

\author{
Integrated Waste Management - Volume I \\ Edited by Mr. Sunil Kumar
}

ISBN 978-953-307-469-6

Hard cover, 538 pages

Publisher InTech

Published online 23, August, 2011

Published in print edition August, 2011

This book reports research on policy and legal issues, anaerobic digestion of solid waste under processing aspects, industrial waste, application of GIS and LCA in waste management, and a couple of research papers relating to leachate and odour management.

\title{
How to reference
}

In order to correctly reference this scholarly work, feel free to copy and paste the following:

Jan Jezierski and Krzysztof Janerka (2011). Solid Waste Utilization in Foundries and Metallurgical Plants, Integrated Waste Management - Volume I, Mr. Sunil Kumar (Ed.), ISBN: 978-953-307-469-6, InTech, Available from: http://www.intechopen.com/books/integrated-waste-management-volume-i/solid-waste-utilization-infoundries-and-metallurgical-plants

\section{INTECH}

open science | open minds

\section{InTech Europe}

University Campus STeP Ri

Slavka Krautzeka 83/A

51000 Rijeka, Croatia

Phone: +385 (51) 770447

Fax: +385 (51) 686166

www.intechopen.com

\section{InTech China}

Unit 405, Office Block, Hotel Equatorial Shanghai

No.65, Yan An Road (West), Shanghai, 200040, China

中国上海市延安西路65号上海国际贵都大饭店办公楼405单元

Phone: +86-21-62489820

Fax: +86-21-62489821 
(C) 2011 The Author(s). Licensee IntechOpen. This chapter is distributed under the terms of the Creative Commons Attribution-NonCommercialShareAlike-3.0 License, which permits use, distribution and reproduction for non-commercial purposes, provided the original is properly cited and derivative works building on this content are distributed under the same license. 